Raúl Silva Castro.

\title{
PARADOJA SOBRE LAS GLASES SOCIALES EN LA LITERATURA
}

TSTAN de moda los panoramas literarios, y seguramente si a cada uno de los escritores chilenos hubiese un editor que le pidiera uno de esos trabajos de conjunto, tendríamos muchos panoramas. No es que un panorama me parezca a mí muy fácil de trazar. Pero cada escritor anhela fijar en la forma más grata a sus ambiciones la situación de su tiempo, el ámbito que lo rodea. Si a uno le dan una habitación en una casa, llevará a ella una serie de objetos que querrá tener consigo para hacerse la existencia más cómoda. Del mismo modo, el escritor considera a sus colegas como objetos destinados a llenar un papel en su relación con su tiempo. Pero no temáis: no pretendo hacer un panorama literario, no porque no tenga deseos sino meramente por falta de editor. Don Julio Vicuña Cifuentes ha cantado en unos versos primorosos el valor de la ocasión, y ha dicho:

- ¿Quién pudo ajar tu honra si tú no lo quisiste?

-La ocasión, madre, la ocasión.

El editor es al escritor lo que la ocasión a la doncella 
cuya honra ajada preocupa al poeta. Muchos libros no se escriben porque no hay posibilidad de que se publiquen, y este tal vez sea su mejor destino. Es muy frecuente oír decir: "iQué bello libro puede escribir Fulano con todo lo que sabe y lo que ha vivido!» El libro se escribe, pero no es sino un muerto más para llenar espacio en las bibliotecas. No basta saber mucho ni recordar mucho para escribir un buen libro. Pero si no pretendo hacer un panorama literario, por falta de editor, sí me interesa ir fijando etapas o hitos para tal tarea que algún día-editor mediante-acaso intente. Hoy me interesa dedicar un poco de atención a una cualidad singular de la literatura chilena. Conviene tener presente que digo singular no en el sentido exclusivista o prescindente de la palabra, sino en el sentido meramente aumentativo. Creo que el rasgo que voy a señalar en la literatura chilena se presenta con parejos caracteres en las demás literaturas americanas. Esto se debe sin duda a las similitudes sociológicas de la formación de estos pueblos. En suma, reducida a una simple proposición, mi tesis es la siguiente: La literatura chilena es una literatura de la cual están ausentes todos los grandes problemas de la vida y todas las inquietudes de la inteligencia.

Quiero decir con esto no que la literatura deba mirar hacia objetivos ajenos a ella misma, para servirlos; no que la literatura deba ser aplicada o tendenciosa. Sino que en la literatura debe sentirse la percusión de los debates del espíritu, sin hacer en estos debates escisiones o cortes premeditados. Desde luego, una obra literaria es un monólogo o un diálogo. Si es monólogo - y naturalmente uso en la palabra en su acepción más lata-, es o debe ser el debate de un hombre consigo mismo. Si es diálogo, un debate entre el hombre- - es decir, el autor-y su sociedad o su ambiente o su grupo social, literario, profesional. Tipos de monólogos o de obras monológicas son en general las 
confesiones o memorias, digamos las de Rousseau. Tipos de diálogo, en general las novelas y especialmente cuando pertenecen al estilo caudaloso y presentativo, como las de Balzac, Dostoyevsky, Stendhal, Tolstoy, Dickens, etc. En el monólogo, el autor, obediente a una fuerza espiritual centrípeta, se contempla a sí mismo como un espectáculo apasionante y se entrega a hacer la exégesis de ese mundo o de esa escena que lleva.dentro. En el diálogo el autor se entrega a una fuerza centrífuga. En esta huída de sí mismo, esencial al novelista, el escritor asume la representación de un grupo de hombres, los retrata, los muestra, y su éxito estriba precisamente en darnos por existentes esos hombres que ha creado, o si los ha observado, en probarnos que es capaz de revestirlos con caracteres tales que los tengamos como creaciones de su imaginación. Creo que esta alternancia de los personajes novelescos no ha sido siempre suficientemente observada. El escritor que inventa debe atender a hacer pasar sus creaturas por seres de carne y hueso. Al revés, el que copia debe deformar tal o cual rasgo a fin de que su realización se ice a la dignidad del retrato y no sea una mera fotografía. Es lo que ha entendido con muy sutil penetración Valle Inclán, y así lo ha mostrado en sus novelas y esperpentos. Los modelos de unas y de otros son hombres que existen o existieron. La novela y el esperpento de Valle Inclán tienen, sin embargo, la trascendental dimensión estética que les reconocemos, gracias principalmente a todo lo arbitrario que surge en ellos, a lo caricatural, a la deformación en fin.

Cuando digo que la literatura chilena es por excelencia una literatura de la cual los problemas han sido amputados, me refiero a la de hoy, o si se quiere a la de los últimos veinte años. No se me oculta que hay en ella muchos nombres respetables y un caudal copioso de obras. No son obras de una calidad exqui- 
sita, destinadas a perdurar sin excepciones, y más bien se muestran como el fruto de una discreta medianía en acción. Dentro del ruedo hispanoparlante de América, la aportación chilena se distingue por su color polvoriento, un poco envejecido y a menudo vulgar. Mientras el Perú acendra el chiste, y entre risas y sonrisas parece ser la propia Andalucía trasladada a América (Palma, Ventura García Calderón), sin perjuicio de una generación joven para la cual existen las ideas (Mariátegui, Basadre, Sánchez), Argentina levanta una novela rica de matices. En ella sólo el estilo torpe, difuso y retorcido estorba a veces para dar al lector una sensación más clara de la materia novelada (Gálvez, Lynch, Quiroga, Güiraldes). En Méjico la cosecha es más rica y más profunda: a la novela densa y muy humana (Azuela), se anexan una lírica de plurales modulaciones (Torres Bodet, Villaurrutia, Pellicer, Gutiérrez Cruz) y una literatura de ideas henchida de sugestiones (Reyes, Vasconcelos, Torri). Colombia sigue siendo el país de los poetas, y eso explica su actual decadencia literaria, ya que la poesía se muestra moribunda, debido tal vez a las sangrías que en ella hicieron algunos de sus hijos des...humanizados. Venezuela ha lanzado a la emigración a sus mejores talentos y la emigración se puebla de voces venezolanas originales, de una notable envergadura y de gran reciedumbre (Pocaterra, Blanco Fombona).

Junto a todo esto llama la atención la pobreza del mensaje chileno, que es tal vez más equilibrado, pero también más anémico. No destaca nuestra novela porque en ella no han alumbrado sino tímidamente los valores humanos (Barrios, Santiván, d'Halmar), ni nuestra lírica, salvo la considerable excepción de Gabriela Mistral ni nuestro ensayo que apenas existe, ni la historia en que antes fuimos grandes $y$ respetados y en cuyo recinto hoy se vive de lo ya 
trabajado, investigado $\mathrm{y}$ descubierto por dos generaciones de más aliento (Barros Arana, Sotomayor Valdés, Amunátegui; Medina, Bulnes). Pero a esta pobreza formal, la literatura chilena une lo que he calificado ya de ausencia de problemas e inquietudes. Nuestra literatura de hoy, salvo sin duda la excepción de Pedro Prado, se mueve en torno a ciertos temas dominantes en que todos o casi todos los escritores creen encontrar matices nuevos, y sin que haya otro impulso a extravagar que el de algunos-muy pocos-escritores que a copiar prefieren inventar. Lo que yo echo de menos en esta literatura es la preocupación por las ideas generales y cierta angustia metafísica que hoy levanta su vuelo en casi todas las demás literaturas del mundo. Se me dirá, seguramente, que para llevar a la literatura ese género de preocupaciones es necesario que el escritor habite un pueblo en el cual existan en mayor o menor grado tales inquietudes. La objeción es insuficiente. El escritor es el producto de una minoría, y la minoría desde la cual él se lanza a explorar el mundo de las formas, que sigue su carrera y corona sus triunfos, es siempre una minoría para la que la inteligencia existe y los problemas espirituales tienen realidad y a veces urgencia.

De allí que en un país de burgueses satisfechos como Francia, sea posible encontrar elementos literarios tan novedosos como los que en nuestros días y siempre han tenido expresión en la lengua de Racine. Desde este punto de vista bastaría, pues, con que hubiese una minoría de hombres para los cuales los problemas vitales y las inquietudes del espíritu existiesen, para que una literatura contara con la traducción literaria de esos problemas e inquietudes. Ahora bien, esa minoría se da en Chile, y por eso me parece anómalo que la literatura chilena siga siendo un producto $\tan$ filisteo, tan anodino. 
Si tendemos la mirada hacia un pequeño número de eminencias europeas de la literatura, encontraremos que los problemas que reflejan en sus obras son numerosos y apasionantes en grado egregio. En Francia, por ejemplo, se ve desde luego a Gide, un escritor combatido con saña por algunos enemigos, no precisamente de su talento, que es enorme, sino de su vida. Gide ha creado una obra en que los problemas de la personalidad ocupan un sitio dominante. Sus novelas benefician la teoría del acto gratuito $y$ sus obras de ideas oscilan entre el romanticismo o el desenfreno de los deseos mal contenidos y el clasicismo o la medida que la razón impone. No: no veremos jamás conforme a este hombre, que se combate mucho más que pueden combatirlo sus más furiosos enemigos y que seguramente se discute a sí mismo con mejor lógica que la de sus contradictores. También es francés Cocteau, que es sin duda un Frégoli de la literatura, ya que de libro a libro cambia de traje y también de postura y que alternativamente se presenta librepensador y católico. Hoy, como la moda de ser escritor católico ha pasado ya en todo país que no sea Chile, Cocteau olvida su teología y sus arrebatos de converso, para trazar en sus Enfants terribles el diagnóstico de una generación impiadosamente azotada por el destino. En Inglaterra ha muerto ayer no más D. H. Lawrence, un escritor ante el cual se abrieron muchas simas y cuyo pensamiento fué siempre asaltado por las serpientes del bien y del mal, especialmente del mal. Para él han existido los problemas más angustiosos, de la misma manera que existen para Chesterton, para Wells, para Huxley y para muchos otros, entre los cuales ocupa lugar destacado el popularísimo Shaw. G. B. S., en efecto, ha escrito sus piezas teatrales $\mathrm{y}$, sobre todo, sus famosos prefacios para combatir y combatirse. Los problemas que ha levantado Shaw en sus obras son casi tan 
numerosos como ellas, y es esto sin duda lo que da al teatro de este escritor las dimensiones inquietantes que todos reconocen en él. En España uno de los escritores dotados por el destino de más angustiosos problemas es sin duda Unamuno, cuya preocupación metafísica y cuyas inquietudes no cesan de atormentarle desde el día, ya un poco lejano, en que nacieron sus primeros ensayos y sus primeros libros. También hay problemas en Pío Baroja, y en algunos escritores jóvenes, aparentemente muy poco afines con estos dos hombres, como Jarnés, Marichalar, Espina, etc., los problemas literarios (estilo, composición, límites de la vida y el arte), tienen una parte que parece inalienable. En Italia hay también escritores para los cuales la literatura es una manera de exponer conflictos espirituales y morales y un escenario donde estudiar lo más valioso del hombre. Pirandello ha llegado a romper las formas sólitas del teatro, a fin de dar cabida en él a la traducción escénica de las inquietudes y problemas que angustian a sus creaciones. Papini, por su parte, un poco Hércules de feria por su gritería estentórea y su afán de derribar, tiene una parte duradera de su obra que está consagrada a estudiar la inquietud metafísica del hombre y primero, naturalmente, la de él.

Para todos los escritores citados y para muchos otros que sería prolijo nombrar, la literatura, muy alejada de lo tendencioso, literatura pura casi siempre, es un vehículo destinado a llevar hasta el lector las inquietudes del hombre que es el autor. Los problemas de la época se reflejan en esa literatura y amoldan situaciones y personajes destinados a encarnarlos y exponerlos. En suma, lo general no está excluído de esta literatura que sabe también, como no podía ser de otra manera, explotar lo particular.

La nuestra, en cambio, la chilena, sólo en lo particular ahonda, sólo en lo particular se complace. Allí 
también se esteriliza y se reduce por sí misma la universalidad de su divulgación (1).

¿A qué se debe este carácter de la literatura chilena que-ya lo he dicho-aparece también en las demás literaturas americanas? Las observaciones que siguen tienden a dar respuesta a esta interrogación.

$$
\text { ** * }
$$

Las Constituciones políticas dicen pomposamente: "Todos los hombres son iguales», y desde cierto punto de vista esto es efectivo. Las sociedades, sin embargo, se ordenan de otra manera. Existen en ellas, en efecto, capas parejas a las geológicas en que unas descansan sobre otras. Pero mientras en la tierra las capas se muestran en equilibrio, en reposo, en la sociedad están

(1) Creo que esta idea debe ser explicada más prolijamente, y a riesgo de fatigar, intentaré hacerlo en esta nota. Llamo general al sentimiento o a la idea que alberga indistintamente el hombre de cualquier tierra $y$ de cualquier tiempo, por ejemplo, el sentimiento de la inquietud metafísica. Esta inquietud la expone detenidamente Unamuno, en El sentimiento trágico de la vida en los hombres y en los pueblos. Como materia novelesca ha sido examinada por muchos escritores de ayer y de hoy. En otros rangos del mismo grupo de sentimientos figuran algunos de los muchos problemas que suscitan las obras de Dostoyevsky, en las cuales se ve al hombre en conflicto consigo mismo o con los demás. No hay, en efecto, novela alguna del gran escritor ruso que no levante por lo menos uno de esos problemas, y la grandeza incontrovertible de Los hermanos Karamazof reside precisamente en que allí están acumuladas las inquietudes y los problemas hasta el punto de quə cada personaje representa o simboliza una inquietud $y$ un problema por lo menos.

En América en el último tiempo se ha intentado la novela de aliento épico, que es el calificativo más exacto que corresponde a Doña Bárbara, Dcn Segundo Sombra, La vorágine, etc., conforme la indicación-muy acertadade Mariano Picón Salas. Pero en Chile se ha visto una curiosa excepción a este movimiento $\mathrm{y}$, despecho de todas las incitaciones, nuestros escritores siguen explotando lo particular.

Llamo particular al sentimiento o a la idea que se da sólo en ciertas circunstancias: determinado medio, época histórica definida y carácter individual preciso; es decir, lo que siente o puede sentir un hombre aislado, pero no siente otro ni otros. De allí arranca el fatal localismo de nuestra literatura de hoy. Lo curioso es que se ha pretendido hacer de este localismo un mérito. Yo, a riesgo de quedar solo en esta apreciación, entiendo que el localismo es uno de los defectos fundamentales de nuestra literatura, y creo deber de todo escritor combatirlo. Tal es el objeto de esta Paradoja. 
continuamente agitadas. Las capas geológicas existen meramente, en tanto que las capas sociales viven. $\mathrm{Si}$ se distinguen tres clases-no hay necesidad de distinguir mayor número-, se verán pasar de una clase a la contigua ciertos elementos poco afectos a la disciplina social. En el trascurso de pocas generaciones una familia se rebaja de grado o se eleva en la escala. De las superiores que han perdido la fortuna se forman familias de la clase media inconformes con su destino. De esta misma clase media surgen tanto aristócratas como plebe. Para lo primero el concurso del dinero es indispensable. Para lo segundo no es necesario tanto. La clase media aparece así como un estupendo e hirviente vivero de aristócratas y de plebeyos. A pesar de la constancia y permanencia que la distinguen, esta clase está en continuo movimiento, y lanza miembros de su seno para incrementar la superior y la inferior. La adaptación no es siempre fácil, y por eso hay familias que, favorecidas mucho tiempo por la fortuna, siguen siendo advenedizas en la aristocracia durante años, hasta que ésta, condescendiente, termina por aceptarlas. Al revés, hay familias de la clase media que siguen, en medio del "tercer estado", formando tienda aparte hasta su perfecta asimilación en él o hasta que vuelven al estado intermedio de que habían transitoriamente salido. De estos procesos de transformación se hacen las capas secundarias que forman, dentro de cada clase, nuevas y nuevas divisiones. No las trataré en esta ocasión y para comodidad de mis observadociones consideraré a las tres clases fundamentales en un momento estático de su desarrollo. Como si los resortes de ruptura y adaptación con que cada una cuenta se hubiesen de pronto paralizado.

Ahora bien, en estas tres clases sociales hay sólo dos que toman con soltura la vida: la superior y la inferior. La primera, que ejerce el poder desde tiem- 
pos tradicionales, termina un día por sentirse dispensada de toda disciplina social (1). Una educación tendenciosa hace de sus miembros seres físicamente superiores y, en lo moral, tan seguros de sí mismos que ningún hecho de la vida les parece dotado de fuerza suficiente para retener o desviar sus ímpetus vitales. Con el concurso del dinero se consiguen, además, casi todos los valores corrientes, y, gracias a este apoyo, el hombre de la clase superior no vacila en sentirse dueño de todo, o en el peor de los casos, destinado a serlo un día. Es imperativo en sus gestos y en su voz; tiene conciencia de su superioridad y no le es difícil llegar a concebir que todos los hombres de clase inferior a la suya han nacido para ayudarle a hacer a él su vida, no para vivir la que a aquellos deparó el destino. Si existe la trasmisión de los caracteres adquiridos, es evidente que estos rasgos se depuran y afirman con el paso de las generaciones. Este sencillo hecho da a la vida del hombre de posición un pulso fuerte y firme que no se halla en el miembro de ninguna otra clase social. Lo que el aristócrata quiere está destinado a ser suyo. De allí nacen, en estadios posteriores de su destino, consecuencias disolventes. La atrofia de la voluntad se produce con mayor frecuencia en estos seres para los cuales anhelo expresado es anhelo cumplido. El escepticismo nace de la comprobación incesante del poder envilecedor del dinero. El desprecio a las leyes, de la facilidad con que el dinero y el apellido se sobreponen al imperio de aquellas. Por este motivo las aristocracias hacen mal en mirar con ojos aviesos la ascensión del hombre de la clase media. El mesócrata que sube está destinado a llenar en este proceso de disolución las bajas que en la aristocracia producen los vicios y la saciedad de la vida.

(1) El poder ha pasado en los últimos años a otras manos. 
La clase inferior, en cambio, toma también la vida con soltura, pero lo hace generalmente por desesperación. Se siente sometida y por eso todo le es indiferente. Es fatalista. Odiada por la clase media y despreciada o no atendida por la superior, no vacila en coger lo que halla al paso, sin pensar en las consecuencias. Su bien consiste en tener el pan seguro, y una habilidad manual cualquiera basta para esto. En sus jornadas no abundan las alegrías, y por eso los días de holganza son orgiásticos. Para vivir un año de esclavitud con cierta resignación bastan a menudo cinco o seis días de plena libertad ruidosa. $\mathrm{Si}$ es cierto que las clases superiores son las que preparan, con su escepticismo crítico y con su cinismo, las revoluciones, sólo la inferior encuentra en éstas una válvula de escape. Ese es el sentido de los saqueos y el pillaje al día siguiente de los motines victoriosos. Rasgo común de las clases superior e inferior es el amor libre. En la primera parece ser un instinto expansivo, de antiquísimo origen (el derecho de pernada), que no puede acomodarse a su gusto en el marco estrecho de la monogamia. La mujer ajena es siempre codiciable, y naturalmente la mujer será del hombre que tiene tiempo y dinero para cercarla y seducirla. La virtud resiste difícilmente la presión de un deseo masculino que se convierte a corto plazo en el eje de un complicado mecanismo de satisfacciones del lujo, de las necesidad de figurar y de los apetitos carnales. En la clase inferior el amor libre presenta todos los matices. Tal vez el menos frecuente sea el versátil donjuanismo y sin duda el más constante, la unión libre, parecida en todo al matrimonio, pero desprovista de la esclavitud de éste.

La clase media, en cambio, es sierva de las preocupaciones y mártir de las conveniencias. Metida a manera de cuña entre la clase popular y la aristocrática, siente a la vez la atracción de la riqueza, del lujo y 
del desprecio a la ley, que adivina en la segunda, y el temor a la degradación y a la incuria en que ve sumida a la plebe. Mientras a ésta no le parece posible llegar a convertirse en aristocracia, la clase media rabia por serlo o... por parecerlo. De allí su impetuoso afán por hacer dinero: un cálculo fácil le presenta la acumulación de riquezas como el primer paso para su encumbramiento. Pero si ahonda en el examen advierte que el dinero no basta. Es preciso entonces conquistar también esas difíciles prendas que se denominan con el insuficiente nombre de educación. El aristócrata somete voluntades, y el hombre de clase media al cual se pone en trance de dominar, erige su capricho en ley y anhela sujetar con rudeza dentro de su órbita a todos los elementos de menor entidad que quedan a su alcance. Uno de los caminos más seguros de la liberación económica consiste en abrazar las carreras liberales, y por eso el mesócrata deja el mostrador y el escritorio subalterno para conquistar la práctica de fórmulas que rinden más fruto. Un socorrido refrán chileno dice: "El abuelo mercader, el padre caballero, el nieto pordiosero.» La clase media, optimista, anhela con vehemencia fijar sólo las dos primeras etapas de esa evolución, y quiere detener en el padre caballero ese proceso de alquimia social que la embriaga con sutiles zumos. En esta trayectoria, la clase media descubre el secreto de todas las virtudes. Seguramente es muy hermoso acostarse humilde y despertar poderoso, rico y respetado. Pero lo único seguro es vivir treinta años de trabajos para asegurarse al cabo un poquito de consideración y de bienestar. Por otra parte, el mesócrata sabe que si se le toma en cuenta es a cambio de un proceder intachable. A un hombre que domina una habilidad manual nadie le pregunta si tiene la conciencia y las manos limpias para encomendarle un trabajo. Un aristócrata por su lado siente que cualquiera que sea 
su conducta, su apellido sigue siendo el mismo, su fortuna una garantía de perdón y su linaje una manera de salvavidas en caso de naufragio. El hombre de clase media, temeroso de caer, atrapa el hierro, candente a veces, de la honorabilidad. Limita sus necesidades. $y$ se hace una especie de segunda naturaleza de la constancia, la abnegación y otras virtudes típicas de su clase.

La cautela preside todos sus actos, y cierto misoneísmo de buen parecer es la tónica de su acorde. Con un gesto fuera de pauta compromete su situación; con una voz destemplada echa a rodar su prestigio, naciente o ya establecido. Innovar es la manera más recta de errar, y cuando no se tiene fuerzas suficientes para imponer un error como verdad, lo mejor es renunciar. En un mundo de apariencias, lo fundamental es la corteza, y a los ojos del mesócrata no hay salvación fuera de la medida y del discreto término medio. El hombre de la clase media es tímido porque una larga experiencia le ha enseñado a esquivar las ocasiones de comprometerse. Desprovisto de espíritu creador y de fuerzas impositivas, se somete a la rutina que le indican los usos que imita, y lo invade el pánico cuando le parece que empieza a alejarse de ella.

$$
*^{*} *
$$

Una luz especial ilumina el proceso de nuestra literatura cuando se observa que ella está entregada, con leves excepciones, a hombres mesócratas. En la expresión escrita deben reflejarse los gustos y las costumbres sociales. Una clase social deprimida y siempre temerosa de caer en lo arbitrario no puede crear un arte grande. Si observamos grosso modo la forma en que se han reclutado los escritores chilenos, veremos cómo acuden desde las provincias hasta 
Santiago, generalmente seducidos por el señuelo de la profesión liberal. En Santiago los asalta el veneno literario, y a veces no son capaces de vencer la tentación. Los pichones de abogados, de profesores, de médicos, se convierten en escritores. Cambian la honesta situación del mesócrata por la incierta carrera del artista.

Pero no siempre la cambian: es más discreto apoyar la una en la otra, pues la literatura es aquí de "los medios de vivir que no dan de vivir», al decir de Larra. Estos literatos producidos por la clase media provinciana o santiaguina no pierden ninguno de los rasgos propios de la clase en que han nacido con su incorporación al mundo literario. Como no hay en Chile una clase intelectual con caracteres individuales, el intelectual no se ve precisado a renunciar a su mundo para ingresar al de sus aficiones. En otros tiempos, cuando la vida bohemia no llamaba la atención en el mundo de los artistas, el mesócrata se hacía voluntariamente bohemio. Pero todo eso ha periclitado. Muchos de los bohemios de otros tiempos están ya convertidos a las buenas costumbres y hoy hasta se confiesan y comulgan. Han vivido en dos etapas diferentes de la vida literaria, y mientras no tuvieron sino veinte años hicieron con gusto su papel en el melodrama de la bohemia, más próxima al hampa que al arte. Ahora son honestos padres de familia y deben mirar con íntima vergüenza sus devaneos de juventud. Más deportivo, el literato de hoy es hijo del siglo, y no se asusta del materialismo ni del aparente antiespiritualismo de la época. De allí un cambio de actitud del escritor frente al público. Durante algún tiempo pareció inseparable del escritor la prestancia mesiánica del hombre que guarda las revelaciones más peregrinas. El poeta era un conductor de muchedumbres; el novelista un vengador de oprimidos; todos los escritores, en fin, siervos de mo- 
tivos ajenos al arte mismo y entroncados más con la sociología que con la belleza. Estas actitudes están superadas, y hoy no son pocos los escritores que confiesan hacer literatura como se hace un deporte: con sano intrascendentalismo.

Ahora bien, lo grave es que estos grupos de mesócratas que se han dedicado al cultivo de la literatura han llevado hasta ella todas sus preocupaciones. Su moral estrecha, su rutinarismo de funcionarios, sus minúsculos puntos de vista se reflejan en nuestra literatura. Yo creo que en el arte es indispensable cierta dosis de arbitrariedad, y ¿cómo podrá poner arbitrariedad en su obra escrita una clase social que ha debido prescindir de cualquier cantidad de ella por miedo a las consecuencias, o simplemente por miedo a la vida, y que se siente opresa por las conveniencias y el buen parecer? De allí que la literatura del mesócrata se mueva en un círculo de diámetro breve, y de allí también que de ella parezcan expulsadas para siempre la alegría de lo arbitrario y hasta las sonrisas del feliz escepticismo. El gusto de la aventura, la divagación sobre temas trascendentales, la arbitrariedad habitual, la lucha contra la moral ambiente, la inquisición de mundos imaginarios, la persecución de módulos barrocos están excluídos de tal literatura, y si en ella aparecen, es justo reconocer su estado embrionario. Sobre ella pesa la mediocridad del hombre cuya vida entera no es sino mediocridad. El distintivo de esta literatura es su egoísta realismo, y uno de sus perfiles más frecuentes su miedo rastrero a la poesía. La originalidad tampoco se da como cosa sólita en esta literatura de términos mediocres, corrompida por lo convencional y poco anhelosa de espacios libres y nuevos. Como la originalidad es difícil de conseguir y como a menudo al perseguirla se cae en lo grotesco, los escritores se conforman con repetirse unos a otros o con repetir a modelos fáciles del 
extranjero. Las innovaciones se reducen a meros detalles, que caben en una pauta estrecha, de escasísimas modulaciones personales. También es frecuente que se repitan las mismas notas a lo largo de varios libros y se insista, sin temor de lindar con la majadería, en los mismos temas. Esos escritores han tomado la literatura con tan generoso espíritu de rutina como el que se pone al servicio de la burocracia.

$\mathrm{Si}$ me fuera permitido hacer observaciones más personales, podría insistir en cada uno de estos caracteres y citar pruebas copiosas que se hallan en los textos mismos de nuestra literatura contemporánea. Pero yo también soy mesócrata y temo las iras de mis compañeros y no puedo librarme de considerar este problema desde el punto de vista del buen parecer. Baste hacer notar que escapan a estos caracteres nefastos sólo unos pocos escritores en quienes han podido darse, con feliz coincidencia, fermentos de inquietud que los han arrojado fuera del círculo de las conveniencias mesocráticas. De acuerdo con todo lo dicho, no creo que sea una mera coincidencia la lejanía entre nuestra literatura y todos los problemas espirituales y morales que agitan hoy la conciencia de los escritores de otros países. ¿Qué problemas ha tocado o rozado siquiera el grupo-sin duda numeroso-de nuestros escritores? ¿En cuáles de sus obras se da cabida, bajo el manto de las letras, a las inquietudes del hombre de hoy? ¿Qué matiz nuevo del mundo se refleja en las literatura chilena? Si uno se asoma a las literaturas europeas, las ve erizadas de problemas porque es lógico que los problemas, especialmente los espirituales, se reflejen en la expresión escrita. Hay escritores a los cuales interesa por sobre todo el destino del hombre; para otros la cuestión se plantea entre la libertad y el determinismo, y en muchas novelas, dramas y ensayos se hallan formas estéticas de este conflicto. No pocos 
escritores inspiran su literatura en el problema de la personalidad, y la filosofía de lo inconsciente encuentra en libros literarios, a veces un antecedente $y$ otras veces una continuación o aplicación de sus inducciones. Llegando más al fondo de estos debates sobre la personalidad, que sobre todo preocupan a los novelistas, se ha llevado a la literatura la teoría del acto gratuito. En muchas novelas se analiza el problema sexual, cuya inquietante magnitud no hace sino aumentar a medida que el hombre inquiere en él y trata de perforar con sus miradas de miope la sima oscura. En fin, cada obra literaria nacida en esos pueblos muestra un flanco ligado a un problema ideológico, moral, psicológico o meramente de costumbres, con lo cual la literatura se vincula a la necesidad de saber más sobre su destino y su vida individual y colectiva, que siente el hombre de estos días. Nuestra literatura, desgraciadamente, tiene los ojos cerrados y se mueve en una órbita pequeñita y sin trascendencia. Los hombres que la cultivan parecen no sentir la presión que sobre ellos ejercen los acontecimientos del mundo en torno o no tener curiosidad de explicarse la razón de las inquietudes que los mueven a ellos y a sus semejantes. Desde este punto de vista, nada más cómodo que ser escritor en Chile. Como no se ahonda en nada, no se corre el peligro de ser discutido, y si eso buscan los escritores chilenos, puede decirse que han dado con el camino que un día deben haber perseguido.

Así como en la clase media se dan las virtudes familiares y domésticas con profusión, así también en nuestra literatura encontramos a cada paso honorables medianías. Nuestra literatura en ese sentido es la democracia de la meseta. Más elevada en términos generales que las de otros países americanos, no ofrece en cambio grandes figuras descollantes, y en vez de un hombre de genio nuestra docenas de 
talentos tranquilos y discretos. Como lo arbitrario está excluído de ella, es difícil tropezar con grandes disparates; tan difícil casi como dar con una expresión genial, de las destinadas a sobrevivir.

Una advertencia final. Si en el curso de estas observaciones he nombrado a algunos escritores extranjeros, téngase presente que no es por simple afán comparativo. Es preciso ponerse en guardia contra ese prejuicio generalizado. Si he citado a algunos escritores de gran circulación en el mundo, no es porque pretenda que nuestros escritores deban repetir los módulos que en aquellos muestra la obra literaria. Yo veo en ellos una especie de metas hacia las cuales debemos correr, de blancos sobre los cuales enderezar nuestras flechas. Hace poco uno de nuestros compañeros, don Januario Espinosa, dijo que un crítico chileno, Alone, había hecho o estaba haciendo en Chile obra pareja a la Sainte-Beuve en Francia. Pues bien, ciertos periodistas, empeñados sin duda en probar que el periodista es un señor que no entiende nada y escribe de todo, dijeron que Espinosa había comparado a Alone con Sainte-Beuve. Y es que en la vida literaria hay una relatividad -0 , si se quiere, una proporcionalidad-estricta. Es preciso no perderla de vista si se anhela tener visión clara de estos problemas. Decía, pues, que los autores extranjeros citados no deben ser tomados por nosotros como modelos o paradigmas. Pero es indudable que en su actitud frente a la vida, frente al arte, frente a los problemas humanos, hay mucho que aprender. Y esta debe ser la conclusión de estos inconexos apuntes. 